Article

\title{
Exploring the Adequacy of Massive Constructed Public Housing in China
}

\author{
Xiaolong Gan ${ }^{1, *}$, Jian Zuo ${ }^{2}$, Tao Wen ${ }^{1}$ and Yujuan She ${ }^{3}$ \\ 1 College of Economics and Management, Southwest University, Chongqing 400715, China; \\ wentao@swu.edu.cn \\ 2 School of Architecture \& Built Environment, University of Adelaide, Adelaide 5000, Australia; \\ Jian.zuo@adelaide.edu.au \\ 3 School of Civil Engineering and Architecture, Chongqing University of Science \& Technology, \\ Chongqing 401331, China; 1999005@cqust.edu.cn \\ * Correspondence: tomkan@swu.edu.cn; Tel.: +86-023-6825-1229
}

Received: 9 March 2019; Accepted: 29 March 2019; Published: 2 April 2019

\begin{abstract}
Public housing programs are an effective strategy to provide adequate housing, not only in developed countries, but also developing countries. This study holistically investigates the sitting occupants' perception of adequate housing towards their public housing units using Chongqing, a typical city in western China, as a case study. Results showed that generally, the public rental housing (PRH) programs were perceived to be adequate by their residents in the estates sampled. The components of neighborhood environment, housing unit, and affordability were the top three factors affecting the overall housing adequacy. The importance of physical aspects as well as the nonphysical aspects of adequate housing is likely to change according to their residential purpose. Therefore, the residential purpose of residents should be taken into consideration when planning the physical and nonphysical elements of public housing programs. Meanwhile, socioeconomic characteristics of age, family income, family members, residence length, and housing types have significant effects on overall housing adequacy and its components. These findings shed some useful insights on the sustainable development of public housing in China and provide a useful reference for future public housing developments in developing countries. The provision of adequate housing also helps to attract and retain talent, which consequently improves the competitiveness of the city.
\end{abstract}

Keywords: housing adequacy; public housing; neighborhood environment; housing unit; affordability

\section{Introduction}

Adequate housing refers to housing that is fundamental in meeting the physiological, psychological, health, and security needs of occupants [1]. It serves as the genesis of other necessities of life, such as education and good health, and is of great importance regarding fundamental human rights [2].

To achieve the goal of adequate housing, one of the targets in the Millennium Declarations, an enabling strategy for the improvement of slum dwellings has been promoted by the UN-Habitat since the late 1980s [3]. The strategy highlights the critical role of the public sector to introduce incentives and facilitate housing actions to upgrade informal settlements and develop public housing [4]. Public housing programs are presented with significant financial constraints and land shortage. As a result, public housing is often constructed in an economic and timely manner without taking residents' needs and aspirations into consideration. According to Turok [5], a focus on delivering bricks and mortar can become a numbers game that relegates the qualities of housing, and inadequacy has been tagged as a common characteristic of public housing [1]. 
The ultimate goal of public housing programs is to assist the poor to escape poverty. This implies that the provision of adequate housing by public housing programs should not only highlight the physical components consisting of the housing and neighborhood, but also meet social and economic needs [6]. It is, therefore, necessary to investigate residents' perceptions in terms of adequate housing, which could provide valuable information required for 'feed-back' into current housing stock as well as 'feed-forward' into future projects. Previous studies have paid greater attention to the physical aspects; few attempts have been made to holistically investigate the situation of public housing in terms of adequate housing. Therefore, this research aims to investigate sitting residents' perceptions of their public housing units in terms of housing adequacy based on survey data collected in Chongqing city, where a huge public housing program has been undertaken. The results will provide empirical evidence for policy intervention to improve public housing residents' life quality as well as shed some light on sustainable development of public housing programs and provide useful evidence on how to improve the performance of future public housing in developing countries.

\section{Public Rental Housing in Chongqing}

Public rental housing (PRH), as the new type of public housing, was introduced and adopted into the mainstream of the massive scale of public housing programs in the National Twelfth Five-Year Plan [7]. The massive-scale public housing program is expected to meet the accommodation needs of a growing number of new entrants who have little hope of purchasing commodity housing, but are likely to live in poor-quality housing, such as migrant workers and recent university graduates. According to Premier Li [8], the massive-scale public housing program serves as a key tool not only to relieve pressure of housing supply shortage, but also to promote urbanization, as well as improve the city's competitiveness.

Located in the west of China, the city of Chongqing plays a critical role in China's Western Development Strategy. In order to achieve one of the urbanization targets of China's National New-Type Urbanization Plan (2014-2020), Chongqing aims to accommodate population growth of nearly 2.07 million people, and as a result, 700,000 dwellings (about 40 million $\mathrm{m}^{2}$ of PRH) have been constructed since 2011. The target population for PRH includes local residents with housing difficulties, rural-to-urban migrant workers, recent university graduates, and people with special professional talents. Applicants must be at least 18 years old with stable employment and sufficient income to pay rent. There are no household registration requirements or upper-income ceiling for applicants in Chongqing. This is different from other cities, such as Beijing and Hangzhou, where only local urban residents are qualified to apply for PRH and there is an upper-income ceiling. All applicants for Chongqing PRH enter a lottery scheme for eligibility. Rent is set at about $60 \%$ of the market price of similar dwellings (between 8-11 CNY (China Yuan) $/ \mathrm{m}^{2}$ ), and the property management fee is about $1 \mathrm{RMB} / \mathrm{m}^{2}$. The rental period of PRH can be set from 1 year to 5 years, and residents can apply to purchase the dwelling when the lease expires.

In Chongqing, the PRH program is planned to extend across 21 residential districts located near the planned subway stations of 18 new monorail lines in different parts of the main city along the second ring. Currently, eight PRH residential districts (Minxin Jiayuan, Kangju Xincheng, Kangzhuang Meidi, Minan Huafu, Chengnan Jiayuan, Liangjiang Minju, Chengxi Jiayuan, and Yunzhu Shanshui) are occupied by residents. Based on the design standard of PRH (DBJ 50/T-133-2011) issued by the Chongqing Urban and Rural Construction Committee, the PRH residential districts will provide 10\% of the construction area for auxiliary facilities, such as parking, sports, cultural, education, commercial, social management, healthcare, sanitary, and public traffic facilities. These auxiliary facilities should be located conveniently without disturbing the nearby PRH, and the types and sizes should be based on the number of PRH residents. For instance, the sports facilities should be configured on the basis of $0.4 \mathrm{~m}^{2}$ per person, the cultural facilities should be constructed on the basis of $120 \mathrm{~m}^{2}$ per thousand persons, the healthcare facilities should be built on the basis of $30 \mathrm{~m}^{2}$ per thousand persons, and so on. Meanwhile, a diversity of housing sizes is provided, i.e., single studio, one-bedroom, two-bedroom, 
and three-bedroom apartments. Dwelling size corresponds to household size. Households with fewer than two family members only have access to dwellings smaller than $40 \mathrm{~m}^{2}$. By contrast, households with three and four family members can access dwellings up to $60 \mathrm{~m}^{2}$ and $80 \mathrm{~m}^{2}$ in size, respectively. According to the decoration design code for indemnificatory residential buildings (DBJ50-111-2010), PRH units are decorated and serviced prior to delivery to satisfy basic living requirements.

The public housing programs in China has been considered as a resource-draining sector for local governments as they have to provide free land and reduce taxes, but also take charge of its development and management. The significant differences of financial revenue probably result in local governments in developing regions being less motivated to provide high-quality housing in terms of public housing programs. Similar previous studies have been mainly concentrated in developed regions, such as Hangzhou [9], whereas less attention has been paid to the developing regions. Therefore, it is imperative to explore the sitting occupants' perceptions regarding their PRH in terms of adequate housing.

\section{Literature Review}

\subsection{Adequate Public Housing}

Providing adequate housing has been committed to as the chief goal by public housing programs [10-12]. According to Byrne [13], the objective of public housing should not only provide decent shelter, but also improve other aspects of wellbeing, such as the attainment of employment and education, the improvement of physical and mental health, wealth creation, social integration, civic engagement, and so on. In light of this, the basic functions of adequate housing have been highlighted as housing attributes relate to physical aspects as well as nonphysical aspects $[11,14,15]$. With reference to the concept of adequate housing, as defined by [1,10,16-19], the attributes of adequate housing can be generally categorized into nonphysical aspects, e.g., tenure security, affordability, accessibility, and cultural adequacy, and physical aspects, e.g., housing unit, housing services and infrastructures, and neighborhood environment.

\subsection{Nonphysical Aspects}

\subsubsection{Tenure Security}

Tenure security is the cornerstone of the right to adequate housing, which guarantee households a legally enforceable right to protect against forced eviction, harassment, or other threats $[3,18]$. It has a close correlation with individual wellbeing and gives residents the confidence that their tenure is guaranteed for a specified period of time to which they have agreed [16]. Tenure security was perceived to be a critical factor affecting living instability, which can be perceived as involuntarily being forced to move to another place when people have to seek cheaper housing as housing costs increase [20]. It is especially important in China, where people are accustomed to stable living conditions [21].

\subsubsection{Affordability}

The affordability highlights that financial costs related to housing should be at a level that does not threaten or forsake the satisfaction of other basic needs of the individual or the household [22]. It not only includes the housing prices, costs of rental or related services, and the expenditure on housing maintenance or repairs, but also the expenditure on transportation and other living costs such as food, clothing, healthcare, and so on $[18,23,24]$. At the same time, the homeownership affordability was often overlooked, which drives low-to-middle-income homeowners to tolerate a much higher financial burden, affecting their housing affordability [25]. 


\subsubsection{Accessibility}

Adequate housing should be accessible, or readily attainable, to those entitled to it. The accessibility requires the freedom from discrimination in access to housing and related services based on sex, race, or any other status [26]. Meanwhile, the housing rights of disadvantaged groups, such as the elderly, the physically disabled, HIV-positive individuals, persons with persistent medical problems, and other vulnerable groups should be ensured some degree of priority consideration. Related law and policy on housing should not only consider their special housing needs, but also provide them more freedom to choose their preferred housing type and size $[9,25]$. Low-income or subsidized housing must be made available to persons in need of assistance, and can also be provided to low-to-middle-income households who feel 'squeezed' by the polarizing housing markets and thus also have limited access to homeownership [25].

\subsection{Cultural Adequacy}

Cultural adequacy requires that the construction, materials, components, and policies relating to housing should incorporate and reflect cultural identity and diversity [26]. More specifically, the housing design should be in accord with local residents' natural lifestyle, and the materials and appearance of the building should express the local cultural value $[27,28]$. At the same time, space and facilities should be available for the implementation of cultural activities [3,29].

\subsection{Physical Aspects}

\subsubsection{Housing Unit}

The aspect of the housing unit mainly includes the housing size, function, layout, indoor environment, and so on [9]. The layout and size of the bedroom(s), common entrance, kitchen, and bathroom were identified as the important attributes for residential satisfaction [23,30,31]. At the same time, the numbers of bedrooms per household have been viewed as an important issue of human housing rights [32]. The attributes of the indoor environment, such as lighting, ventilation, noise insulation, and thermal and humidity comfort, have also been suggested to affect quality of life $[1,27,33]$. The quality of housing materials and workmanship, structural durability and safety, and appropriateness of location were also found to seriously affect the livability of housing [34]. The privacy, flexibility, functionality, and provision of necessary amenities within housing should be considered in housing design, which have been suggested to seriously affect residential satisfaction $[16,20,30]$.

\subsubsection{Housing Services and Infrastructures}

Related services and infrastructures have been viewed as the strongest predictor of life satisfaction [31]. Adequate housing should be sustainable and provide nondiscriminatory access to basic energy supplies ranging from water, gas, electricity, and telecommunication to cable television [35,36]. Basic housing support infrastructures, such as sanitary and drainage facilities, lighting facilities, garbage disposal and recycling facilities, and firefighting facilities, should be available in communities [31,32,37]. The number and location of elevators and the road networks are also emphasized as critical attributes of adequate housing $[19,38]$.

\subsubsection{Neighborhood Environment}

The aspect of the neighborhood environment has been adopted as one of the critical dimensions evaluating housing adequacy $[19,23]$. As Hettige and Paranagama [18] argued, adequate housing should not to be located within hazardous zones and have access to community resources. That is to say, public facilities should be available within the neighborhood environment, ranging from public transportation, medical care, sport and recreational, education, and handicapped and social 
welfare to traffic vehicle parking [30,31,39]. Besides, throughout occupancy, the facility management services must be sufficient concerning security, cleaning and maintenance, and leisure and landscape needs $[31,35]$. The community facilities must be available as well as the commercial facilities $[23,33]$. Meanwhile, housing is not adequate if it is cut off from employment opportunities [3]. Distance to the workplace has been highlighted as an important issue in the neighborhood of public housing [37]. It is especially important for low-income households that ample business and employment opportunities exist in their neighborhood environment $[24,31]$.

\subsection{Research Framework}

Housing adequacy is usually based on a complexity of subjective and objective parameters associated with individuals' previous experience, cultural values, personal attributes, perceptions, aspirations, goals, and needs as well as generally defined and acceptable standards [1]. The adequacy level is a function of how housing attributes are perceived by an individual and the standard reference to which such attributes are compared. This can be demonstrated by the fact that a residential environment might be perceived by some people as being highly adequate, while for others, it may be inadequate [19]. Thus, the housing adequacy as a contextual conception has direct association with individuals' socioeconomic characteristics [40]. The conceptual framework is shown in Figure 1.

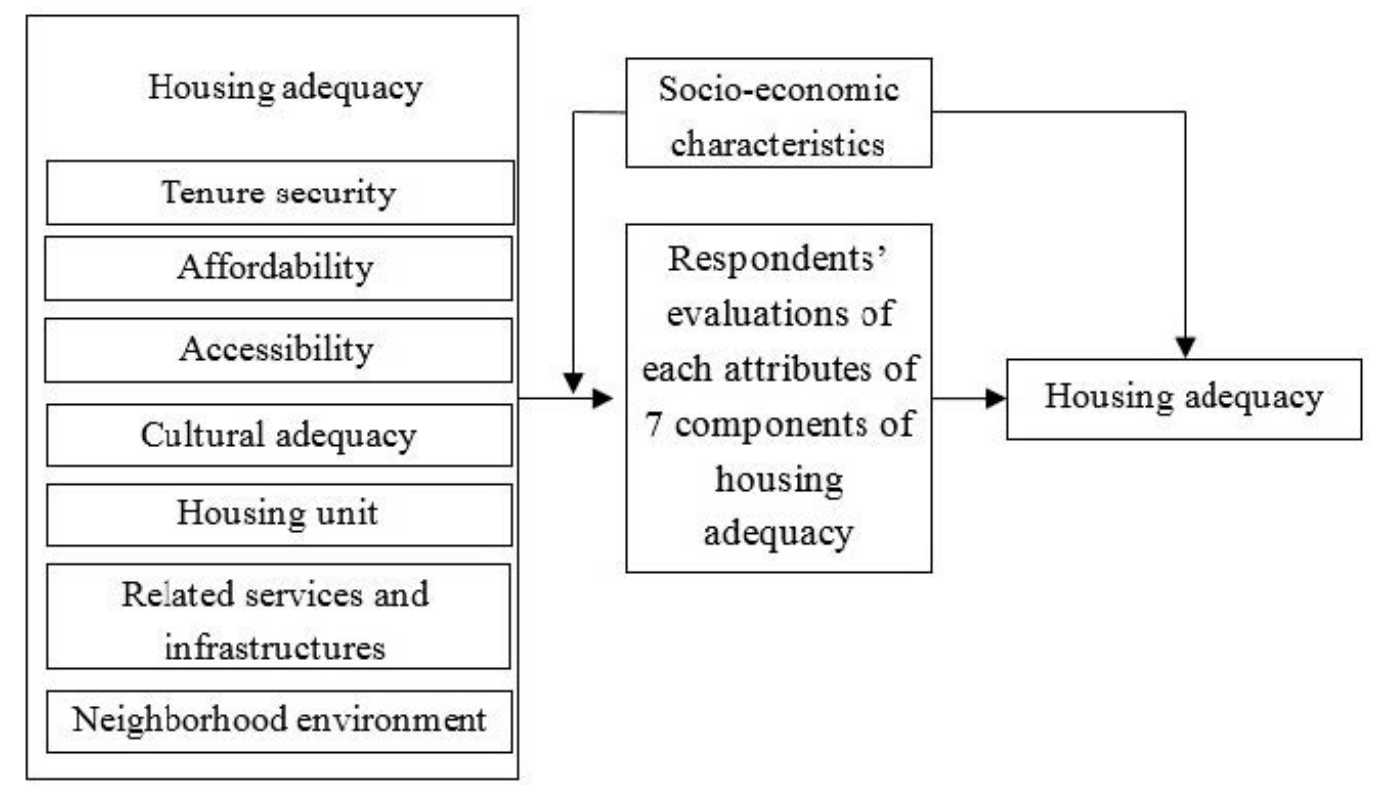

Figure 1. The conceptual framework of this study.

\section{Research Methodologies}

A hybrid research methodology was adopted in this study. Firstly, an extensive literature review was conducted to identify the specific attributes of adequate housing. Consequently, a questionnaire survey was conducted to elicit public housing residents' perceptions of overall adequacy level as well as these attributes of adequate housing by using a five-point Likert scale. Finally, the overall housing adequacy as well its critical factors could be identified by using statistical analysis tools.

\subsection{Identifying the Attributes of Adequate Housing}

A total of 47 attributes of adequate housing were identified from literature review (Table 1). 
Table 1. Results of housing adequacy from literature review.

\begin{tabular}{|c|c|c|}
\hline Code & Attributes of Housing Adequacy & Key References \\
\hline \multicolumn{3}{|c|}{ Nonphysical Aspects } \\
\hline \multicolumn{3}{|c|}{ Tenure Security } \\
\hline HA1 & Legal security of tenure & {$[18,41]$} \\
\hline HA2 & Tenure guaranteed for a specified time & [16] \\
\hline \multicolumn{3}{|c|}{ Affordability } \\
\hline HA3 & Price of housing rental and related services & {$[23,24]$} \\
\hline HA4 & Expenditure on transportation & {$[23,24]$} \\
\hline HA5 & Disposable income to cover other living costs & {$[24,31]$} \\
\hline HA6 & Access to limited homeownership with lower price & {$[25]$} \\
\hline \multicolumn{3}{|c|}{ Cultural Adequacy } \\
\hline HA7 & Design of residence in relation to local residents' natural lifestyle & [27] \\
\hline HA8 & Materials and appearances of buildings expressing local cultural value & {$[27,28]$} \\
\hline HA9 & Spaces and facilities for cultural activities & {$[3,29]$} \\
\hline \multicolumn{3}{|c|}{ Accessibility } \\
\hline HA10 & Unprejudiced allocation regulations & [26] \\
\hline HA11 & Freedom to choose preferred type and size & {$[9,25]$} \\
\hline HA12 & Opportunity for limited ownership after five years of occupancy & [25] \\
\hline \multicolumn{3}{|c|}{ Physical Aspects } \\
\hline \multicolumn{3}{|c|}{ Housing Unit } \\
\hline HA13 & Numbers of bedrooms per household & [32] \\
\hline HA14 & Space and layout of kitchen and bathroom & {$[23,30]$} \\
\hline HA15 & Size and layout of common entrance & {$[9,23,31]$} \\
\hline HA16 & Size and layout of bedrooms & {$[30,31]$} \\
\hline HA17 & Thermal and humidity comfort in the residence & {$[31,42]$} \\
\hline HA18 & Natural lighting and ventilation of the indoor environment & {$[31,42]$} \\
\hline HA19 & Quality of building materials and workmanship & {$[34]$} \\
\hline HA20 & Amenities of kitchen and bathroom & {$[27,33]$} \\
\hline HA21 & Structural durability and safety & [34] \\
\hline HA22 & Privacy within units & {$[23,30]$} \\
\hline HA23 & Functionality of unit layout & {$[23,30]$} \\
\hline HA24 & Insulation from external airborne noise & {$[31,33]$} \\
\hline HA25 & Appropriateness of location for residential purpose & {$[31,34]$} \\
\hline HA26 & Indoor environment flexibility & [43] \\
\hline \multicolumn{3}{|c|}{ Housing Services and Infrastructure } \\
\hline HA27 & Supply of telecommunications, water, electricity, gas, and cable television & {$[35,36]$} \\
\hline HA28 & Sanitary and drainage facilities & {$[30,37]$} \\
\hline HA29 & Lighting facilities & {$[28,32]$} \\
\hline HA30 & Numbers and location of elevators & {$[19]$} \\
\hline HA31 & Road networks & [19] \\
\hline HA32 & Garbage disposal and recycling facilities & {$[31,37]$} \\
\hline HA33 & Firefighting facilities & {$[30,31]$} \\
\hline \multicolumn{3}{|c|}{ Neighborhood Environment } \\
\hline HA34 & Public transportation facilities & {$[30,37]$} \\
\hline HA35 & Medical care facilities & {$[37,44]$} \\
\hline HA36 & Commercial facilities & [9] \\
\hline HA37 & Sport and recreational facilities & [31] \\
\hline HA38 & Education facilities & {$[31,45]$} \\
\hline HA39 & Facilities for handicapped and social welfare & {$[37,45]$} \\
\hline HA40 & Community management facilities & {$[9,36]$} \\
\hline HA41 & Traffic vehicle parking facilities & [33] \\
\hline HA42 & Business and employment opportunities & {$[24,37]$} \\
\hline HA43 & Management measures regarding life and property security & {$[31,35]$} \\
\hline HA44 & Cleanliness and maintenance services within estate & {$[31,35]$} \\
\hline HA45 & Spaces for children to play in & {$[46]$} \\
\hline HA46 & Landscape, scenery, or green areas & [35-37] \\
\hline HA47 & Distance to workplace & {$[31,37]$} \\
\hline
\end{tabular}




\subsection{Questionnaire Survey}

The questionnaire survey was conducted in the eight completed and occupied PRH residential districts. The questionnaire design was based on the 47 attributes identified by literature review. The questionnaire included three sections. The first section was designed to collect respondents' socioeconomic characteristics, ranging from gender, age, marital status, income, education, employment sector, and number of family members to housing type. The second section served to measure the adequacy level of the 47 attributes identified by literature review by using a 5 -point Likert scale ( 1 = very inadequate, $2=$ inadequate, $3=$ slightly inadequate, $4=$ adequate, and $5=$ very adequate). In the third section, respondents were required to express their opinion on the overall housing adequacy of their residential environment by using a 5-point Likert scale. Before conducting the formal survey, the questionnaire was pilot-tested with 30 randomly selected migrant workers in the PRH. Based on the results of the pilot test, the questionnaire was improved, mainly in order to avoid ambiguous expression of some questions. The questionnaire survey was conducted by using the convenience sampling approach to recruit respondents who were identified within their residential districts. This sampling approach has been regarded as appropriate way to address availability issues of potential respondents, which has been commonly adopted in previous studies where a questionnaire survey has been conducted [39]. A total of 1002 valid responses were received, which is a relatively large sample size compared with those of previous studies $[9,23]$.

\subsection{Data Analysis Methods}

The adequacy index proposed by Ibem and Amole [1] was adopted to explore the adequacy level of PRH. This method was also applied by Addo [47] to investigate the residential satisfaction of low-income households in Accra. The adequacy index can be categorized into four regions: very inadequate $(-)=20-39$; inadequate $(-)=40-59$; adequate $(+)=60-79$; and very adequate $(++)=80-100$. Using Equation (1), the adequacy index for each housing attribute can be computed:

$$
A I_{j}=\frac{\sum_{i=1}^{i=N} y_{i j}}{\sum_{i=1}^{i=N} Y_{i j}} \times 100
$$

where $A I_{j}$ is the adequacy index of a housing attribute, $j ; Y_{i j}$ is the maximum possible score of housing attribute $j ; y_{i j}$ is the actual score given by respondents, $i$, regarding attribute $j$; and $N$ represents the number of respondents.

The adequacy index of a component can be examined using Equation (2):

$$
A I_{\mathcal{C}}=\frac{\sum_{i=1}^{i=N} y_{i}}{\sum_{i=1}^{i=N} Y_{i}}
$$

where $A I_{C}$ is the adequacy index of a component, $C$, as given by a respondent; $N$ is the number of variables being scaled under $C ; y_{i}$ is the actual score by a respondent on the $i_{t h}$ variable; and $Y i$ is the maximum possible score that the $i_{\text {th }}$ respondent could give with the scale used.

The stepwise regression was conducted to identify the critical component of overall housing adequacy. The overall adequacy level is the independent variable, and the adequacy index of each component are the dependent variables. This approach has been adopted in similar studies to identify the key determinants of residential satisfaction [32,48].

The technique of analysis of variance (ANOVA) was used to examine the effect of socioeconomic characteristics on the overall housing adequacy and its components. ANOVA was also applied by Chen to test the existence of between-group differences in residential satisfaction [49]. 


\section{Data Analysis}

\subsection{Housing Adequacy Index}

The adequacy index of the overall residential environment was 68.507, indicating that respondents generally perceived their residential environment as being adequate. More than half of respondents perceived their residential environment to be slightly inadequate ( 3 = slightly inadequate), followed by nearly $40 \%$ of residents perceiving it to be adequate $(4=$ adequate). The proportion of those who perceived inadequacy ( $2=$ inadequate) was only $1 \%$. It is interesting to notice that none of the respondents perceived their residential environment as being very inadequate $(1=$ very inadequate $)$ or very adequate ( 5 = very adequate).

By using the housing adequacy index, as shown in Figure 2, tenure security (TS) was suggested by respondents as being very adequate (80.3). It is the highest adequacy level compared with other components of adequate housing. The accessibility (AC) had the next highest score of perceived adequacy (AD) (75.03), followed by cultural adequacy (CA) (72.65), housing unit (HU) (69.49), housing services and infrastructure (HI) (67.43), and affordability (AF) (64.99). It deserves to be noticed that affordability was the only component which had an adequacy index lower than the components of the physical aspects, e.g., housing unit, housing services, and infrastructure. Meanwhile, the neighborhood environment was the only component with an inadequate level.

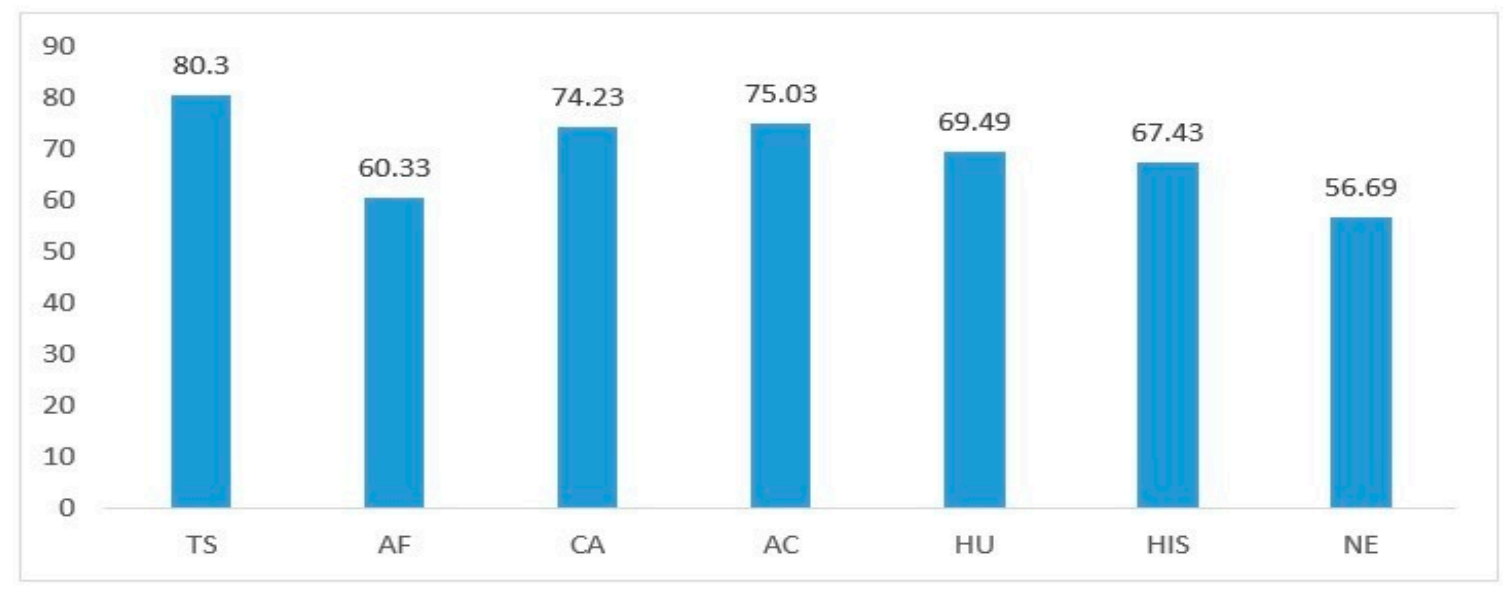

Figure 2. Adequacy index of seven aspects of adequate housing. TS = tenure security; AF = affordability; $\mathrm{CA}=$ cultural adequacy; $\mathrm{AC}=$ accessibility; $\mathrm{HU}=$ housing unit; $\mathrm{HIS}=$ housing services and infrastructure; $\mathrm{NE}=$ neighborhood environment.

As shown in Table 2, the adequacy index of nonphysical aspects (72.478) as perceived by respondents was higher than that of the physical aspects, with the adequacy index of 64.535 . In terms of nonphysical aspects, four attributes were perceived as very adequate, including legal security of tenure (HA1), tenure guaranteed for a specific time (HA2), design of residence in relation to local residents' natural lifestyle (HA7), and materials and appearance of building expressing local cultural value (HA8). The former two attributes were related to tenure security, and the last two attributes were related to cultural adequacy. Meanwhile, three attributes were perceived as being inadequate: Two attributes were related to affordability (AF), namely expenditure on transportation (HA4) and disposable income to cover other living costs (HA5). These two attributes were mainly related to the issue of non-housing expenditure. This indicates that there is no improvement regarding the aspect on non-housing expenditure for PRH residents. The inadequacy of the attributes of cultural adequacy (HA9), e.g., spaces and facilities for cultural activities, suggest that there is a lack of spaces and facilities for cultural activities. 
Table 2. Housing adequacy index (HAI) of the attributes of adequate housing.

\begin{tabular}{|c|c|c|c|c|c|c|c|c|c|}
\hline Component & Codes & Mean & HAI & Region & Component & Codes & Mean & HAI & Region \\
\hline \multicolumn{5}{|c|}{ Nonphysical Aspects } & \multicolumn{5}{|c|}{ Physical Aspects } \\
\hline \multirow{2}{*}{ TS } & HA1 & 4.06 & 81.28 & ++ & \multirow{3}{*}{$\mathrm{HU}$} & HA24 & 3.75 & 74.97 & + \\
\hline & HA2 & 3.97 & 79.32 & ++ & & HA25 & 3.32 & 66.47 & + \\
\hline \multirow{4}{*}{$\mathrm{AF}$} & HA3 & 3.11 & 62.24 & + & & HA26 & 3.41 & 68.14 & + \\
\hline & HA4 & 2.94 & 58.80 & - & \multirow{7}{*}{ HSI } & HA27 & 3.06 & 61.16 & + \\
\hline & HA5 & 3.00 & 59.96 & - & & HA28 & 3.38 & 67.54 & + \\
\hline & HA6 & 3.95 & 78.96 & + & & HA29 & 3.16 & 63.15 & + \\
\hline \multirow{3}{*}{ CA } & HA7 & 4.13 & 82.63 & ++ & & HA30 & 3.39 & 67.86 & + \\
\hline & HA8 & 4.14 & 82.75 & ++ & & HA31 & 4.13 & 82.67 & + \\
\hline & HA9 & 2.63 & 52.57 & - & & HA32 & 3.44 & 68.82 & + \\
\hline \multirow{3}{*}{$\mathrm{AC}$} & HA10 & 3.93 & 78.56 & + & & HA33 & 3.04 & 60.80 & + \\
\hline & HA11 & 3.67 & 73.49 & + & \multirow{14}{*}{ NE } & HA34 & 3.19 & 63.87 & + \\
\hline & HA12 & 3.65 & 73.05 & + & & HA35 & 2.82 & 56.45 & - \\
\hline \multicolumn{5}{|c|}{ Adequacy Index of ANP $=72.478$} & & HA36 & 2.55 & 51.10 & - \\
\hline \multicolumn{5}{|c|}{ Physical Aspects } & & HA37 & 3.18 & 63.67 & + \\
\hline \multirow{11}{*}{$\mathrm{HU}$} & HA13 & 3.85 & 77.05 & + & & HA38 & 2.55 & 51.10 & - \\
\hline & HA14 & 3.32 & 66.47 & + & & HA39 & 3.04 & 60.88 & + \\
\hline & HA15 & 2.62 & 52.38 & - & & HA40 & 2.97 & 59.32 & + \\
\hline & HA16 & 2.82 & 56.33 & - & & HA41 & 2.94 & 58.80 & + \\
\hline & HA17 & 3.58 & 71.54 & + & & HA42 & 1.73 & 34.65 & - \\
\hline & HA18 & 4.18 & 83.67 & ++ & & HA43 & 2.32 & 46.35 & - \\
\hline & HA19 & 2.94 & 58.80 & - & & HA44 & 1.71 & 34.25 & - \\
\hline & HA20 & 4.06 & 81.28 & ++ & & HA45 & 2.96 & 59.28 & + \\
\hline & HA21 & 4.00 & 80.00 & ++ & & HA46 & 4.10 & 82.00 & ++ \\
\hline & HA22 & 3.18 & 63.67 & + & & HA47 & 2.90 & 57.96 & - \\
\hline & HA23 & 3.60 & 72.02 & + & & uacy & 101 & 64.535 & \\
\hline
\end{tabular}

Notes: Very inadequate $(-)=20-39$; inadequate $(-)=40-59$; adequate $(+)=60-79$; very adequate $(++)=80-100$; $\mathrm{TS}$ = tenure security; $\mathrm{AF}=$ affordability; $\mathrm{CA}=$ cultural adequacy; $\mathrm{AC}=$ accessibility; $\mathrm{HU}$ = housing unit; $\mathrm{HIS}=$ housing services and infrastructure; $\mathrm{NE}=$ neighborhood environment, $\mathrm{ANP}$ = adequacy level of nonphysical aspects; APA = adequacy level of physical aspects.

With regard to physical aspects, four attributes were perceived as being very adequate, ranging from natural lighting and ventilation of the indoor environment (HA18), amenities of the kitchen and bathroom (HA20), structural durability and safety (HA21), and landscape, scenery, or green areas (HA46). The former three attributes were related to the housing unit (HU), while the latter one was related to the neighborhood environment (NE). Meanwhile, it deserves notice that ten attributes were perceived as being inadequate: seven attributes related to the neighborhood environment (NE) and three attributes related to the housing unit (HU). This is in line with the adequacy level of NE, with the lowest adequate index compared to other aspects. The inadequate attributes of NE include medical care facilities (HA35), commercial facilities (HA36), education facilities (HA38), business and employment opportunities (H42), management measures regarding life and property security (H43), cleanliness and maintenance services within the estate (HA44), and distance to workplace (HA47). Most of these attributes are concerned with employment, public services, and community security and management. The attributes of HU with inadequate levels were the size and layout of the common entrance (HA15), size and layout of bedrooms (HA16), and indoor environment flexibility (HA26). These attributes were related to housing design.

\subsection{Stepwise Regression}

By using stepwise regression, the results show that all the seven aspects have significant $p$-values and a positive relationship with overall housing adequacy. As shown in Table 3, these seven aspects account for nearly $80 \%$ of the overall variance. Based on the standardized beta coefficient presenting the relative influence in predicting the overall housing adequacy, the most influential aspect is the 
neighborhood environment, accounting for about $40 \%$ of the variance, followed by housing unit and affordability, with nearly $18 \%$ and $10 \%$ of the variance, respectively. The three aspects together account for about $65.1 \%$ of the variance. The rest of the aspects include housing infrastructure and services, cultural adequacy, accessibility, and tenure security, together accounting for $13 \%$ of the variance. Meanwhile, it can be concluded that the influence of physical aspects, accounting for $63.1 \%$ of the variance, is higher than that of the nonphysical aspects, accounting for nearly $15 \%$ of the variance.

Table 3. Results of stepwise regression.

\begin{tabular}{ccccccccc}
\hline \multirow{2}{*}{$\begin{array}{c}\text { Independent } \\
\text { Variables }\end{array}$} & \multicolumn{2}{c}{$\begin{array}{c}\text { Unstandardized } \\
\text { Coefficients }\end{array}$} & $\begin{array}{c}\text { Standardized } \\
\text { Beta }\end{array}$ & $\mathbf{T}$ & Sig & $\mathbf{R}^{\mathbf{2}}$ & Adjust. $\mathbf{R}^{\mathbf{2}}$ & $\mathbf{\Delta R}^{\mathbf{2}}$ \\
\cline { 2 - 7 } & $\mathbf{B}$ & Std & & & & & & \\
\hline NE & 0.31 & 0.004 & 0.508 & 79.056 & 0.000 & 0.385 & 0.384 & 0.385 \\
HU & 0.294 & 0.005 & 0.437 & 64.192 & 0.000 & 0.591 & 0.56 & 0.176 \\
AF & 0.149 & 0.003 & 0.361 & 57.689 & 0.000 & 0.632 & 0.651 & 0.091 \\
HIS & 0.062 & 0.002 & 0.193 & 24.673 & 0.000 & 0.723 & 0.722 & 0.071 \\
CA & 0.091 & 0.004 & 0.179 & 25.743 & 0.000 & 0.755 & 0.754 & 0.032 \\
AC & 0.067 & 0.003 & 0.161 & 24.058 & 0.000 & 0.779 & 0.778 & 0.024 \\
TS & 0.021 & 0.002 & 0.065 & 8.392 & 0.000 & 0.782 & 0.781 & 0.003 \\
\hline \multicolumn{7}{c}{ Notes: dependent variable = overall housing adequacy. }
\end{tabular}

\subsection{One-Way ANOVA}

As shown in Table 4, the socioeconomic characteristics of family income, number of family members, residence duration, and housing types have significant effects on the overall housing adequacy. Meanwhile, the socioeconomic characteristics of family income and number of family members significantly affect the adequacy level of affordability. Respondents' education level was founded to have a significant effect on the cultural adequacy. The component of housing unit was affected by family income, number of family member, residence duration, and housing types. The adequacy of the neighborhood environment was found to be affected by the socioeconomic characteristics of age, education, family income, number of family members, residence duration, and housing types.

Table 4. Results of one-way ANOVA.

\begin{tabular}{ccccccccc}
\hline Variables & TS & AF & CA & AC & HU & HIS & NE & OHA \\
\hline \multirow{2}{*}{ GEN } & 2.56 & 0.007 & 0.339 & 2.763 & 1.215 & 0.512 & 0.387 & 0.262 \\
& $(0.11)$ & $(0.931)$ & $(0.561)$ & $(0.097)$ & $(0.271)$ & $(0.474)$ & $(0.534)$ & $(0.609)$ \\
\hline \multirow{2}{*}{ AGE } & 1.773 & 0.192 & 1.571 & 1.976 & 1.393 & 1.012 & 4.025 & 0.791 \\
& $(0.151)$ & $(0.902)$ & $(0.196)$ & $(0.117)$ & $(0.244)$ & $(0.387)$ & $(0.008)^{* *}$ & $(0.5)$ \\
\hline \multirow{2}{*}{ EDU } & 0.409 & 2.1 & $2.976^{*}$ & 0.742 & 0.799 & 0.044 & $3.643^{* *}$ & 1.869 \\
& $(0.802)$ & $(0.8)$ & $(0.019)$ & $(0.564)$ & $(0.526)$ & $(0.996)$ & $(0.006)$ & $(0.115)$ \\
\hline \multirow{2}{*}{ MAR } & 0.121 & 0.482 & 1.142 & 2.618 & 1.691 & 0.371 & 0.645 & 0.601 \\
& $(0.886)$ & $(0.618)$ & $(0.32)$ & $(0.074)$ & $(0.185)$ & $(0.69)$ & $(0.525)$ & $(0.549)$ \\
\hline \multirow{2}{*}{ EMP } & 0.852 & 0.552 & 0.665 & 0.73 & 2.368 & 0.404 & 0.532 & 0.412 \\
& $(0.466)$ & $(0.674)$ & $(0.574)$ & $(0.534)$ & $(0.07)$ & $(0.75)$ & $(0.659)$ & $(0.744)$ \\
\hline \multirow{2}{*}{ FIN } & 0.706 & $4.903 * *$ & 1.026 & 0.269 & $3.846^{* *}$ & 0.279 & $6.414^{* *}$ & $2.705^{*}$ \\
& $(0.588)$ & $(0.001)$ & $(0.393)$ & $(0.898)$ & $(0.004)$ & $(0.891)$ & $(0.000)$ & $(0.03)$ \\
\hline \multirow{2}{*}{ FAM } & 0.43 & $3.443^{* *}$ & 0.971 & 0.783 & $3.773 * *$ & 1.324 & $12.73^{* *}$ & $3.659^{* *}$ \\
& $(0.787)$ & $(0.009)$ & $(0.423)$ & $(0.536)$ & $(0.005)$ & $(0.26)$ & $(0.000)$ & $(0.006)$ \\
\hline \multirow{2}{*}{ RD } & 0.967 & 0.434 & 1.904 & 2.289 & $21.845^{* *}$ & 0.398 & $14.393^{* *}$ & $3.044^{*}$ \\
& $(0.408)$ & $(0.729)$ & $(0.128)$ & $(0.078)$ & $(0.000)$ & $(0.754)$ & $(0.000)$ & $(0.029)$ \\
\hline \multirow{2}{*}{ HUP } & 1.365 & 0.365 & 0.558 & 2.933 & $7.532 * *$ & 0.422 & $4.174 *$ & $3.015^{*}$ \\
& $(0.256)$ & $(0.694)$ & $(0.573)$ & $(0.054)$ & $(0.001)$ & $(0.656)$ & $(0.016)$ & $(0.05)$ \\
\hline
\end{tabular}

Notes: $* *$ significant at the 0.01 level, ${ }^{*}$ significant at the 0.05 level. GEN $=$ gender; EDU $=$ education level; MAR = marital status; EMP = employment sector; FIN = family income per month; FAM = number of family members; RD = Residence Duration HUP = housing type. 
Further analysis was conducted to explore the significant effect of these socioeconomic characteristics (e.g., age, education, income, number of family members, residence duration, and housing type) on the overall adequacy level and its components. According to Figure 3, aged respondents perceived a higher adequacy level towards the neighborhood environment than younger respondents. As shown in Figure 4, the well-educated respondents were likely to have lower perceived adequacy level towards neighborhood environment than less-educated respondents. This might indicate that the neighborhood environment of PRH has not sufficiently satisfied the needs of well-educated respondents, but meets the requirements of less-educated respondents. Meanwhile, the well-educated respondents' affordability was obviously higher than less-educated respondents. Higher education might imply higher income. With regard to income, as shown in Figure 5, higher-income respondents, with an implied better situation of affordability, might have higher requirements on the aspects of the housing unit and neighborhood environment than lower-income respondents. Similarly, as shown in Figure 6, it can be said that respondents with more family members perceived lower adequacy levels in the aspects of affordability, housing unit, and neighborhood environment and the overall residential environment. Figure 7 indicates that larger housing size can significantly improve the adequacy level of the residential environment. Larger housing not only increases the adequacy level of the overall residential environment, but also the adequacy level of the housing unit and neighborhood environment, while as shown in Figure 8, Fespondents with longer residence duration might perceive a lower adequacy level regarding the housing unit, neighborhood environment, and overall residential environment.

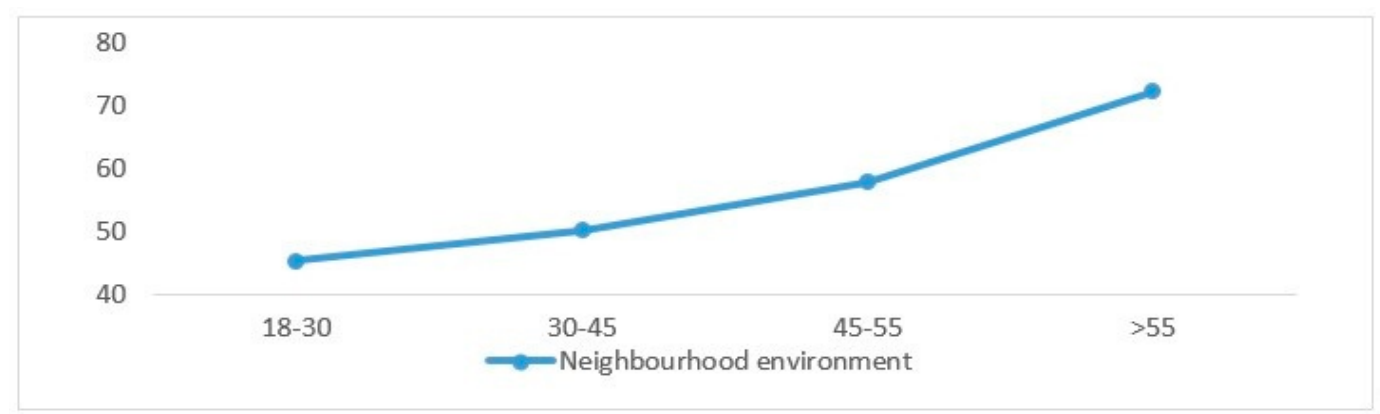

Figure 3. Perceived adequacy level of neighborhood environment grouped by age (AGE).

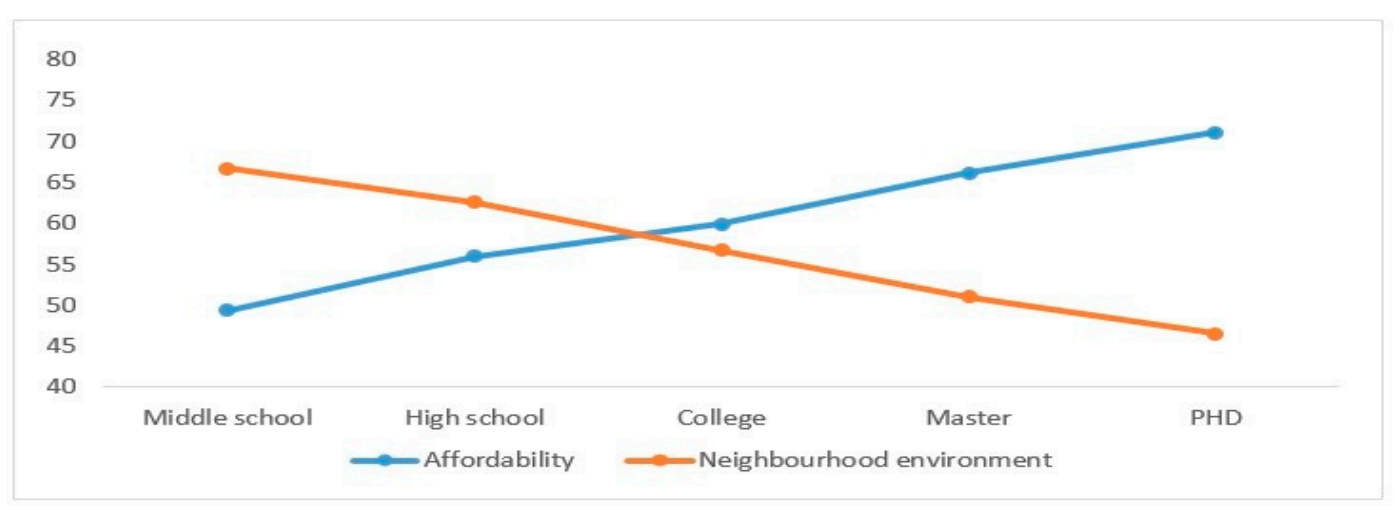

Figure 4. Perceived adequacy level of affordability and neighborhood environment grouped by education (EDU). 


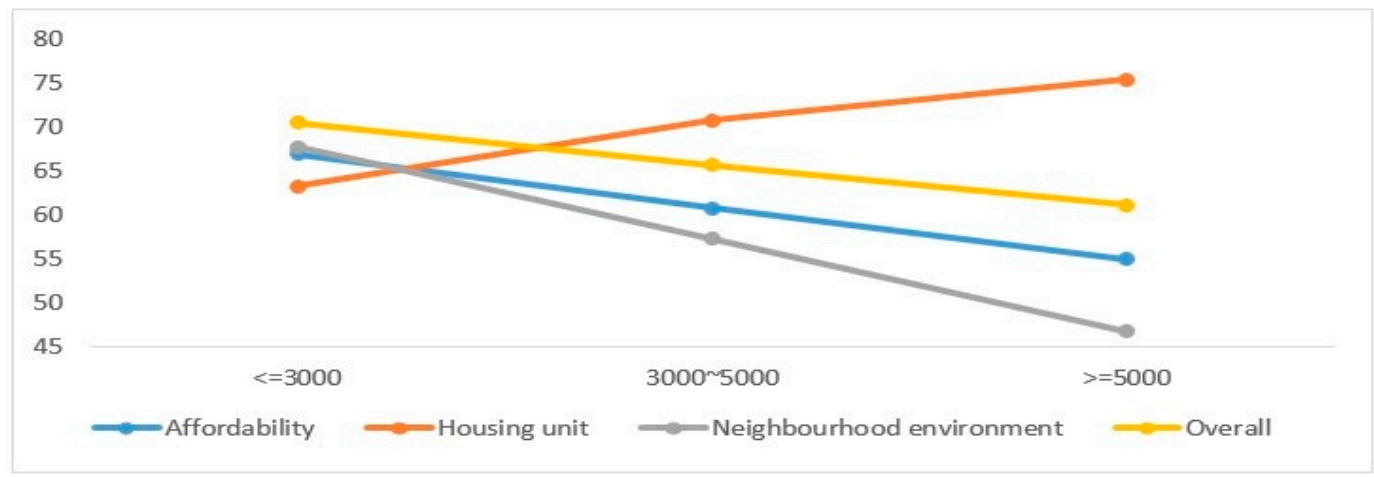

Figure 5. Perceived adequacy level of affordability, housing unit, neighborhood environment, and overall residential environment grouped by income (FIN).

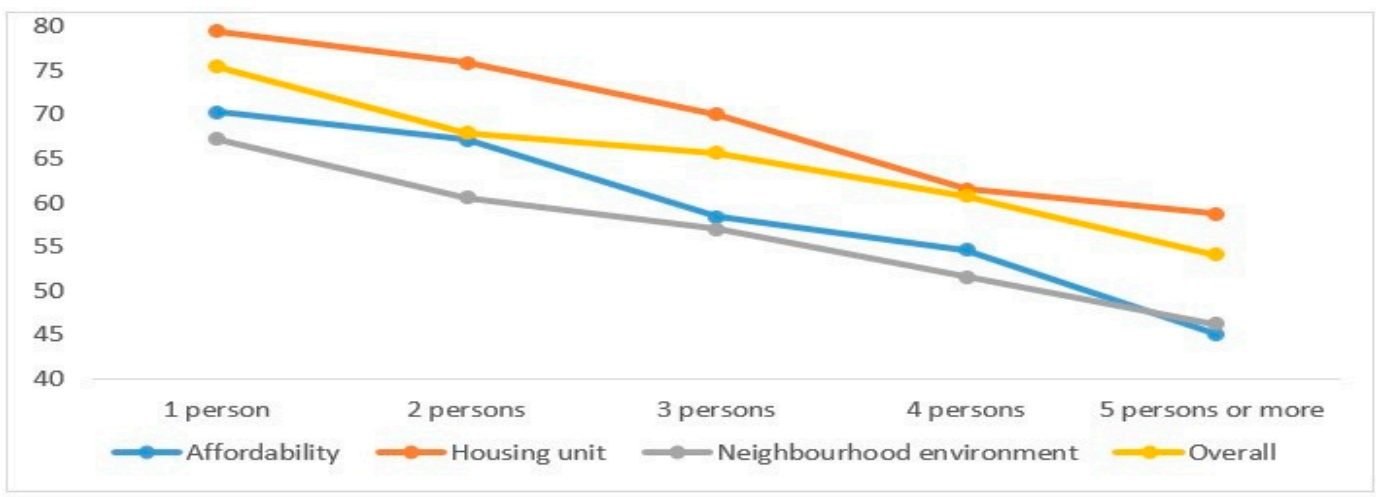

Figure 6. Perceived adequacy level of affordability, housing unit, neighborhood environment, and overall residential environment grouped by number of family members (FAM).

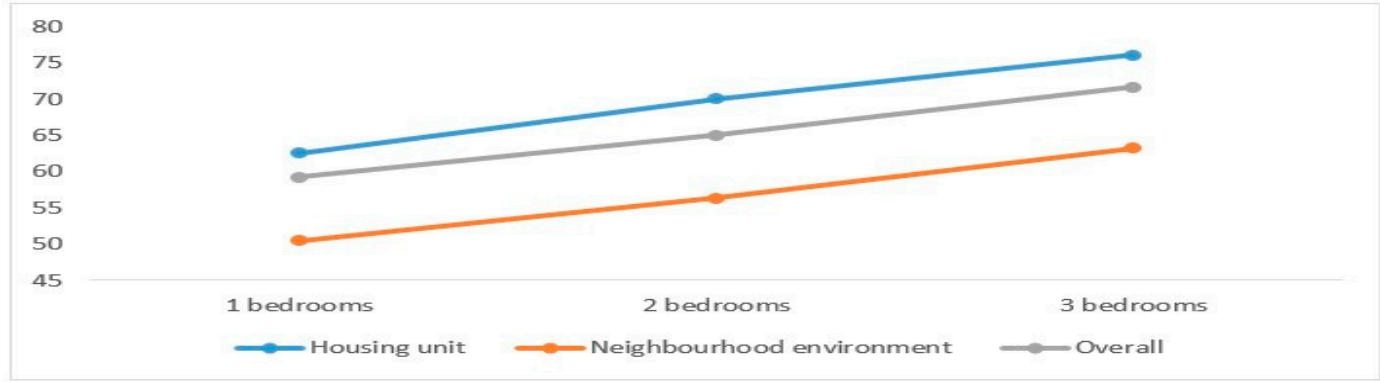

Figure 7. Perceived adequacy level of housing unit, neighborhood environment, and overall residential environment grouped by housing types (HUP).

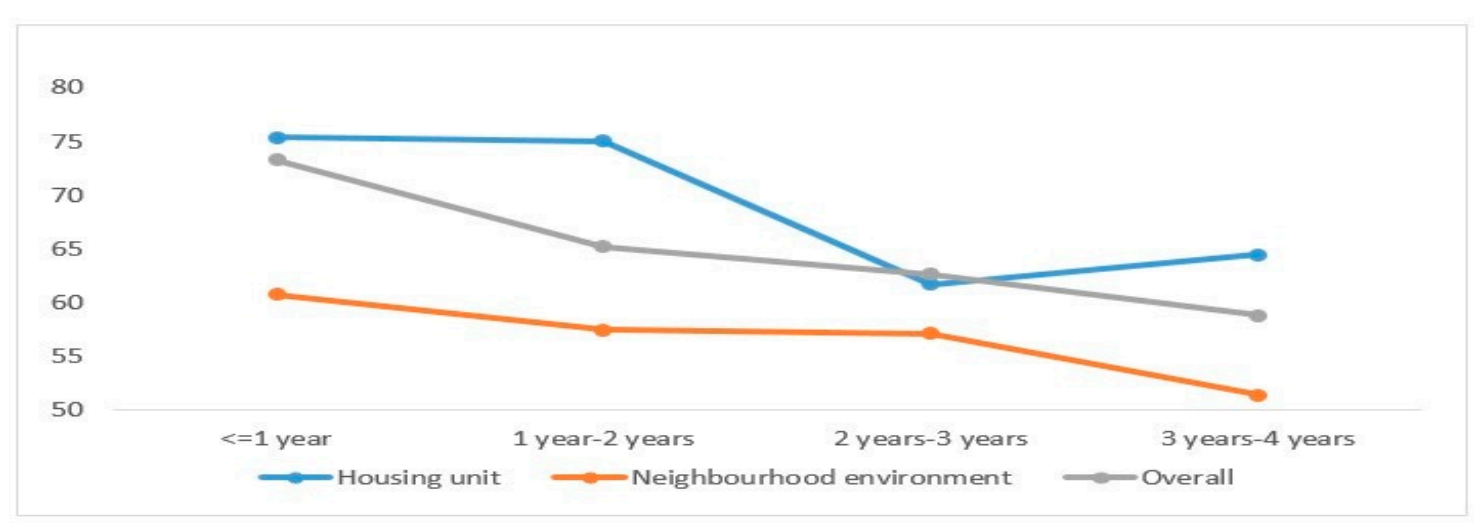

Figure 8. Perceived adequacy level of housing unit, neighborhood environment, and overall residential environment grouped by residence duration (RD). 


\section{Discussion}

As shown in Figure 4, the component of neighborhood environment was the only one with an inadequate level. Previous studies showed that there is a contrast between the satisfaction with the neighborhood environment and satisfaction with the housing unit $[30,46]$. Thus, the 'trade-off' of different components of adequate housing will take place in public housing programs across different countries. The compromised component of neighborhood environment probably implies the unfulfilled goal of providing adequate housing through public housing in Chongqing, as the sufficient quantity remains the priority.

As shown in Table 3, the inadequacy of the level of the neighborhood environment was due to medical care facilities (HA35), commercial facilities (HA36), educational facilities (HA38), traffic parking facilities (HA41), employment opportunities (HA42), facility management (HA43), and distance to workplace (HA47). This is mainly because the PRH programs in Chongqing are primarily located in the urban-rural fringes [23]. As greater economic revenue can be gained by developing commercial housing in areas with adequate public services, there is little incentive for local governments to develop public housing programs in such areas. Meanwhile, the location of public housing in the urban fringes may lead to jobs-housing mismatch [24]. As a consequence, the affordability deteriorated due to increases in non-housing expenditure. This is represented by the inadequate level of two attributes of affordability, namely expenditure on transportation (HA4) and disposable income to cover other living costs (HA5). Meanwhile, it deserved notice that the level of spaces and facilities for cultural activities (HA9) was inadequate. This probably suggested that the cultural needs have been highlighted by these occupants, and they felt that spaces and related facilities for cultural activities in the public housing were lacking. Similarly, three attributes of the housing unit were perceived to be inadequate, namely the size and layout of the common entrance (HA15), size and layout of the bedroom (HA16), and quality of building materials and workmanship (HA19). These issues were related to housing design and quality. As Gan et al. [50] highlighted, tight budget and schedule can result in poor housing quality.

All seven components of adequate housing were found to significantly affect the overall adequacy (Table 4). This highlighted the important role of physical aspects as well as nonphysical aspects in achieving adequate housing. This research finding complements previous studies that overlooked the nonphysical aspects $[30,46,47]$. The standardized coefficient implies the important level of each component on the overall adequacy [51]. The results of stepwise regression (Table 3) tend to suggest that higher importance has been placed on the physical aspects, such as the neighborhood environment and housing unit, ranking first and second respectively, than the nonphysical aspects. This is partly in conflict with the findings of [23], which reported that more importance was placed by migrant workers on the nonphysical aspects of informal housing, especially the housing costs. As Lin and Li [52] argued, migrant workers living in informal housing can maximize their savings by minimizing their living costs. This is arguably because informal housing has been regarded as a temporary residence in order to achieve their economic purpose. The higher importance placed on the physical aspects probably implies that the public rental housing in Chongqing is not considered as their temporary residence, but instead their permanent accommodation in the city. Therefore, the importance of physical aspects and nonphysical aspects are likely to change accordingly based on the residential purpose.

The results of one-way ANOVA suggest the negative effect of education on the adequacy of the neighborhood environment and the positive effect of education on the adequacy of affordability. The positive effect implies that the public housing can improve the housing affordability of residents with higher education levels, such as young university graduates, while the negative effect might represent their higher housing expectations. Cui et al. [53] suggested that housing affordability is a significant factor in determining the mobility of young university graduates. In light of this, it can be argued that the 'trade-off' behaviors are likely to take place among these young university graduates when they are confronted with ideal housing being unaffordable. However, the housing affordability of young university graduates is likely to be improved along with work experience 
longevity and the corresponding salary increase [54]. Meanwhile, lower satisfaction resulting in residential stress is closely associated with higher mobility, which is a way of relieving residential stress [51]. Therefore, the ability of public rental housing to attract or retain these talents is transient, which might be ineffective in the long term. Therefore, it is strongly suggested that diversified preferential policies can be provided for these talents, such as providing a housing allowance to these talents to improve their living environment. Meanwhile, low loan interest and tax subsidy can be provided for the first-purchased property. According to Figure 7, residents with higher income were likely to perceive a lower adequacy level of the neighborhood environment as well as overall inadequacy level. This implies that these preferential policies should be also provided to migrant workers to enhance their ability of improving their residential environment.

The negative effects of household size on the adequate level of housing unit and overall housing adequacy were also found, which are inconsistent with findings of previous studies $[25,46]$. The proportion of housing types with more bedrooms should be increased in the future design of public rental housing to cater to the needs of families with more members. This is supported by the positive effect of housing type with more bedrooms on the housing units and overall adequacy level, as shown in Figure 7.

\section{Conclusions}

As the ultimate goal of public housing programs, provision of adequate housing remains a serious challenge in most developing countries. Investigating sitting occupants' perceptions of adequate housing regarding their PRH unit is a possible way to achieve this goal. As previous studies mainly focused on the physical aspects and overlooked the nonphysical aspects, this study aims to fill this knowledge gap by enquiring about the level of housing adequacy of public housing. In total, 47 attributes of adequate housing were identified from nonphysical aspects and physical aspects, and the adequacy level of each attribute as well as the overall adequacy level was investigated using a questionnaire survey. The results indicated that the public housing in Chongqing was adequate, in general. Excepting the component of neighborhood environment, the other six components of adequate housing were perceived to be adequate at least. All the components presented a positive relationship with the overall adequacy level of public housing. The socioeconomic characteristics of age, family income, number of family members, residence duration, and housing types have a significant effect on overall housing adequacy or the seven components thereof. This study has theoretical contributions and practical implications for the provision of adequate housing through public housing programs.

Theoretically, this study suggests that providing adequate housing through public housing programs can motivate migrant workers to permanently relocate to urban areas. This can be regarded as an effective tool to facilitate urbanization and boost economic development. Other developing regions, especially in the western part of China, can learn lessons from Chongqing to make specific innovative policies for public housing programs, such as having no upper-income limit or household registration limitations. Secondly, this study innovatively demonstrated that the importance of physical aspects of adequate housing as well as the nonphysical aspects is likely to change according to their residential purpose. Higher importance will be placed on the physical aspects when considering permanent residential purposes, while nonphysical aspects will be given more importance in temporary residential or economic purposes. Thirdly, the effect of public housing in attracting and retaining residents with higher education might be transient. For those young university graduates with higher housing expectations, their housing affordability will be potentially improved along with working experience longevity. Therefore, it might be ineffective to retain these talents through the public rental housing programs in the long term. Diversified preferential housing policies should be provided for different kinds of labor forces to satisfy their different housing expectations and aspirations.

There are some practical implications from this study. Firstly, due to jobs-housing mismatch, the public transport administration should make preferential public transportation policies, such as 
discounted transportation fees. This can cut down non-housing expenditure and enhance affordability. Secondly, in order to improve the quality of facility management and services, the public revenue department should made preferential policies, such as tax reduction, which can motivate property management companies to provide a higher quality of property management. Thirdly, the public construction management administration should deliver PRH which have been well-equipped with supporting facilities, such as medical facilities, commercial facilities, and education facilities. This can hugely improve the residential quality of PRH. Fourthly, the proportion of housing types with more bedrooms should be increased in the future design of public rental housing programs. Fifthly, for those residents with higher educational attainments, the Chongqing municipal government should provide housing allowances or preferential housing prices or loan interests, as has been adopted in other cities, e.g., Nanjing, Shanghai, and Wuhan. This might be more effective in attracting or retaining them. Consequently, households with low capability of improving their residential environment might have more freedom to choose their preferred housing, such as bigger housing size.

Future research should be conducted in other developing cities to facilitate a more comprehensive comparison. This provides valuable information to the evidence-based policymaking related to the fundamental human rights of having access to adequate housing. Meanwhile, the geographic information system (GIS) could be adopted in further research with the aim to explore effective spatial policies to improve the affordability of PRH for residents.

Author Contributions: The author X.G. conducted the primary work for research design, literature review, and research data collection and analysis. J.Z. and T.W. assisted in literature review, design for data collection, and data analysis. Y.S. contributed in language editing.

Funding: This study was supported by the China Postdoctoral Science Foundation (No. 2017M6229950), Fundamental Research Funds for the Central Universities (No. SWU1409101), Chongqing Social Science Foundation (No. 2017QNGL51), and Chongqing Postdoctoral Science Foundation (No. XM2017155).

Conflicts of Interest: The authors declare no conflict of interest.

\section{References}

1. Ibem, E.O.; Amole, O.O. Assessment of the qualitative adequacy of newly constructed public housing in Ogun State, Nigeria. Prop. Manag. 2011, 29, 285-304. [CrossRef]

2. Terminski, B. The Right to Adequate Housing in International Human Rights Law: Polish Transformation Experiences. Rev. Latinoam. De Derechos Hum. 2011, 22, 219-241.

3. OHCHR. The Right to Adequate Housing; New York Office, Office of the United Nations High Commissioner for Human Rights, United Nations: New York, NY, USA, 2009.

4. Yap, K.S. The enabling strategy and its discontent: Low-income housing policies and practices in Asia. Habitat Int. 2016, 54, 166-172. [CrossRef]

5. Turok, I. Housing and the urban premium. Habitat Int. 2016, 54, 234-240. [CrossRef]

6. Kellekci, Ö.L.; Berköz, L. Mass Housing: User Satisfaction in Housing and its Environment in Istanbul, Turkey. Int. J. Hous. Policy 2006, 6, 77-99. [CrossRef]

7. Gan, X.; Zuo, J.; Chang, R.; Li, D.; Zillante, G. Exploring the determinants of migrant workers' housing tenure choice towards public rental housing: A case study in Chongqing, China. Habitat Int. 2016, 58, 118-126. [CrossRef]

8. Li, K. Massive-scale implementation of security housing program and step-by-step improvement of housing policy and provision system. Qiu Shi 2011, 8, 1-8.

9. Huang, Z.; Du, X. Assessment and determinants of residential satisfaction with public houing in Hangzhou, China. Habitat Int. 2015, 47, 218-230. [CrossRef]

10. Djebarni, R.; Al-Abed, A. Housing adeuqncy in Ymen: An incestigation into physical quality. Prop. Manag. 1998, 16, 16-23.

11. UN-Habitat. The Right to Adequate Housing. Available online: https://www.ohchr.org/Documents/ Publications/FS21_rev_1_Housing_en.pdf (accessed on 1 April 2019).

12. Obeng-Odoom, F. Has the Habitat for Humanity Housing Scheme achieved its goals? A Ghanaian case study. J. Hous. Built Environ. 2009, 24, 67-84. [CrossRef] 
13. Byrne, J.P.; Diamond, M. Affordable housing, land tenure, and urban policy: The matrix revealed. Urban Law J. 2007, 34, 527-612.

14. Opoku, R.A.; Abdul-Muhmin, A.G. Housing preferences and attributes importance among low-income comsumers in Aaudi Arabia. Habitat Int. 2010, 34, 219-227. [CrossRef]

15. Golubchikov, O.; Badyina, A. Sustainable Housing for Sustainable Cities, A Policy Framework for Developing Cities; UN-Habitat: Nairobi, Keny, 2012.

16. Zealand, S.N. The Six Dimensions of Housing Adequacy. Available online: http://www.habitat.org.nz/ about/dimensions.html (accessed on 1 April 2019).

17. Bonnefoy, X. Inadequate housing and health: An overview. Int. J. Environ. Pollut. 2007, 30, 411-429. [CrossRef]

18. Hettige, S.T.; Paranagama, D. Defining Indicators to Measure Adequate Housing in SRI LANKA 2009; Sri SPARC: Sri Jayawardenapura-Kotte, Sri Lanka, 2009.

19. Ibem, E.O.; Alagbe, O.A. Investigating dimensions of housing adequacy evaluation by residents in public housing. Facilities 2015, 33, 465-484. [CrossRef]

20. Tao, L.; Hui, E.C.M.; Wong, F.K.W.; Chen, T. Housing choices of migrant workers in China: Beyond the Hukou perspective. Habitat Int. 2015, 49, 474-483. [CrossRef]

21. Huang, Y.; Clark, W.A. Housing tenure choice in transitional urban China: A multilevel analysis. Urban Stud. 2002, 39, 7-32. [CrossRef]

22. Arslan, Ö. Inhabitants' perspectives on the adequacy of the compound house in Ayigya, Kumasi, Ghana. In Proceedings of the Enhr Conference, Toulouse, France, 5-8 July 2011; pp. 1-16.

23. Li, T.; Wong, F.K.W.; Hui, E.C.M. Residential satisfaction of migrant workers in China: A case study of Shenzhen. Habitat Int. 2014, 42, 193-202.

24. Cai, W.; Lu, X. Housing affordability: Beyond the income and price terms, using China as a case study. Habitat Int. 2015, 47, 169-175. [CrossRef]

25. Ying, Q.; Luo, D.; Chen, J. The determiants of homeownership affordability among the 'sandwich calss': Empirical findings from Guangzhou, China. Urban Stud. 2013, 50, 1870-1888. [CrossRef]

26. Kabir, A.H.M. Development and human rights: Litigating the right to adequate housing. Asia-Pac. J. Hum. Rights Law 2002, 1, 97-119. [CrossRef]

27. Ibem, E.O.; Opoko, A.P.; Adeboye, A.B.; Amole, D. Performance evaluation of residential building in public housing estates in Ogun State, Nigeria: Users' satisfaction perspecrive. Front. Archit. Res. 2013, 2, 178-190. [CrossRef]

28. Liu, A.M.M. Residential satisfaction in housing estates: A Hong Kong perspective. Autom. Constr. 1999, 8, 511-524. [CrossRef]

29. Thiele, B. The human right to adequate housing: A tool for promoting and protecting Individual and community health. Am. J. Public Health 2002, 92, 712-725. [CrossRef]

30. Mohit, M.A.; Ibranhim, M.; Rashid, Y.R. Assessment of residential satisfaction in newly designed public low-cost housing in Kuala Lumpur, Malaysia. Habitat Int. 2010, 34, 18-27. [CrossRef]

31. Ibem, E.O.; Amole, D. Subjective life satisfaction in public housing in urban areas of Ogun State. Nigeria. Cities 2013, 35, 51-61. [CrossRef]

32. Mohit, M.A.; Mahfoud, A.-K.A. Appraisal of residential satisfaction in double-storey terrace housing in Kuala Lumpur, Malaysia. Habitat Int. 2015, 49, 286-293. [CrossRef]

33. Mohit, M.A.; Nzayddh, N. Social housing program of Selangor Zakat Board of Malaysia and housing satisfaction. J. Hous. Built Environ. 2011, 26, 143-164. [CrossRef]

34. Ismail, F.; Jabar, I.L.; Janipha, N.A.I.; Razali, R. Measuring the Quality of Life in Low Cost Residential Environment. Procedia Soc. Behav. Sci. 2015, 168, 270-279. [CrossRef]

35. Lai, J.H.K. Comparative evaluation of facility management services for housing estates. Habitat Int. 2011, 35, 391-397. [CrossRef]

36. Hashim, A.E.; Samikon, S.A.; Nasir, N.M.; Ismail, N. Assessing factors influencing performance of Malaysian low-cost public housing in sustainable environment. Procedia Soc. Behav. Sci. 2012, 50, 920-927. [CrossRef]

37. Salleh, A.G. Neighbourhood factors in private low-cost housing in Malaysia. Habitat Int. 2008, 32, $485-493$. [CrossRef]

38. Kang, N.N.; Kim, J.T.; Lee, T.K. A Study on the Healthy Housing Quality of Multi-family Attached House According to Dwelling Unit Age. Energy Procedia 2014, 62, 595-602. [CrossRef] 
39. Huang, Z.; Du, X.; Yu, X. Home ownership and residential satisfaction: Evidence from Hangzhou, China. Habitat Int. 2015, 49, 74-83. [CrossRef]

40. UN-HABITAT. National Experiences with Shelter Delivery for the Poorest Groups; UN-HABITAT: Nairobi, Kenya, 2006.

41. UN Committee on Economic, Social and Cultural Rights (CESCR). The Right to Adequate Housing (art. 11 (1) of the Covenant); CESCR: Geneva, Switzerland, 1991; p. 13.

42. Zalejska-Jonsson, A.; Wilhelmsson, M. Impact of perceived indoor environment quality on overall satisfaction in Swedish dwellings. Build. Environ. 2013, 34, 134-144. [CrossRef]

43. Maina, J.J. Uncomfortable prototypes: Rethinking socio-cultural factors for the design of public housing in Billiri, north east Nigeria. Front. Archit. Res. 2013, 2, 310-321. [CrossRef]

44. Wang, M.; Yang, Y.; Jin, S.; Gu, L.; Zhang, H. Social and cultural factors that influence residential location choice of urban senior citizens in China - The case of Chengdu city. Habitat Int. 2016, 53, 55-65. [CrossRef]

45. Wang, Y.; Otsuki, T. Do institutional factors influence housing decision of young generation in urban China: Based on a study on determinants of residential choice in Beijing. Habitat Int. 2015, 49, 508-515. [CrossRef]

46. Ibem, E.O.; Aduwo, E.B. Assessment of residential satisfaction in public housing in Ogun State, Nigeria. Habitat Int. 2013, 40, 163-175. [CrossRef]

47. Addo, I.A. Assessing residential satisfaction among low income households in multi-habited dwellings in selected low income communities in Accra. Urban. Stud. 2016, 53, 631-650. [CrossRef]

48. Gan, X.; Zuo, J.; Ye, K.; Skitmore, M.; Xiong, B. Why sustainable construction? Why not? An owner's perspective. Habitat Int. 2015, 47, 61-68. [CrossRef]

49. Chen, G. Housing the urban poor in post-refrom China: Some empirical evidence from the city of Nanjing. Cities 2012, 29, 252-263. [CrossRef]

50. Gan, X.; Zuo, J.; Ye, K.; Chang, R.; Zillante, G. Are migrant workers satisfied with public rental housing? A study in Chongqing, China. Habitat Int. 2016, 56, 96-102. [CrossRef]

51. Chen, K.S.; Chen, H.T. Applying Importance-Performance Analysis with Simple Regression Model and Priority Indices to Assess Hotels' Service Performance. J. Test. Eval. 2014, 42, 20130124. [CrossRef]

52. Lin, S.; Li, Z. Residential satisfaction of migrants in Wenzhou, an 'ordinary city' of China. Habitat Int. 2017, 66, 76-85. [CrossRef]

53. Cui, C.; Geertman, S.; Hooimeijer, P. The mediating effects of parental and peer pressure on the migration intentions of university graduates in Nanjing. Habitat Int. 2016, 57, 100-109. [CrossRef]

54. Li, L.H.; Wu, F.; Dai, M.; Gao, Y.; Pan, J. Housing affordability of university graduates in Guangzhou. Habitat Int. 2017, 67, 137-147. [CrossRef]

(C) 2019 by the authors. Licensee MDPI, Basel, Switzerland. This article is an open access article distributed under the terms and conditions of the Creative Commons Attribution (CC BY) license (http://creativecommons.org/licenses/by/4.0/). 